\title{
Crescimento do pinhão-manso em resposta à adubação fosfatada e à compactação de um Latossolo Vermelho Amarelo sob cultivo em ambiente protegido
}

\section{Jatropha growth in response to phosphate fertilization and compaction of a Red Yellow Latosol under cultivation in a protected environment}

1 Jair Henrique de Castro jair.castro@ifnmg.edu.br

1 Dilermando Dourado Pacheco

2 Tatiane Carla Silva

1 Tiago Mendes Rodrigues

1 Gildarley Costa da Cruz

1 Instituto Federal de Educação, Ciência e Tecnologia do Norte de Minas Gerais - Campus Januária.

2 Universidade Estadual Paulista "Júlio de Mesquita Filho".

\section{RESUMO}

O presente trabalho objetivou quantificar o crescimento de plantas jovens de pinhão-manso submetidas a variações de doses de fósforo $(P)$ e de massas específicas de um solo Latossolo Vermelho Amarelo. Previamente, na microrregião de Januária, foi coletada uma amostra de solo na camada de 20 a $40 \mathrm{~cm}$, certificando-se, em laboratório, da baixa disponibilidade de $\mathrm{P}-1,4 \mathrm{mg} \mathrm{dm}^{-3}$ de $\mathrm{P}-$, a fim de se aplicar os tratamentos de interesse. Foram aplicadas doses de 0,106 e $318 \mathrm{mg} \mathrm{dm}^{-3}$ de P, utilizando-se a fonte superfosfato simples e os solos foram compactados até atingirem massas específicas de solo iguais a 1,53; 1,72 e $1,91 \mathrm{~kg} \mathrm{dm}^{-3}$. As doses de $\mathrm{P}$ e as massas específicas do solo constituíram os nove tratamentos conduzidos em esquema fatorial completo. 0 cultivo foi realizado em vasos de PVC com dimensões de $19,4 \mathrm{~cm}$ de diâmetro interno e $23,5 \mathrm{~cm}$ de altura, com volume útil de $5,912 \mathrm{dm}^{3}$ de solo. 0 crescimento das plantas foi determinado por meio de mensurações de altura de planta, diâmetro de colo, número de folhas e consumo hídrico ao longo do ciclo; e de massa seca de raízes, caule e folha à época da coleta do experimento. Para análise estatística dos dados, fez-se análise de variância, teste de média Tukey e análise de regressão. De modo geral, as características de crescimento das plantas apresentaram resposta mais pronunciada à adubação fosfatada comparada à compressão física testada. As raízes de pinhão-manso foram incapazes de penetrar camada de solo com massa específica de solo igual a $1,91 \mathrm{~kg} \mathrm{dm}^{-3}$.

\section{Palavras-chave:}

Jatropha curcas L.. Consumo hídrico. Biometria da planta. Adubação fosfatada. Compressibilidade de solo.

\section{ABSTRACT}

The present work aimed to quantify the growth of young physic nut plants submitted to variations in phosphorus $(P)$ and specific masses of a Red Yellow Latosol soil. Previously, in Januária micro-region, a soil sample was collected in the 20 to $40 \mathrm{~cm}$ layer, making sure, in the laboratory, the low availability of $P-1.4 \mathrm{mg} \mathrm{dm}-3$ of $P-$ in order to apply the treatments of interest. Doses of 0 , 106 and $318 \mathrm{mg} \mathrm{dm}-3$ of $P$ were applied, using the simple superphosphate source; and the soils were compacted until reaching specific soil masses equal to 1.53; 1.72 and $1.91 \mathrm{~kg} \mathrm{dm}-3$. The doses of $P$ and the specific masses of the soil constituted the nine treatments carried out in a complete factorial scheme. The cultivation was carried out in PVC pots with dimensions of $19.4 \mathrm{~cm}$ in internal diameter and $23.5 \mathrm{~cm}$ in height, with a useful volume of $5.912 \mathrm{dm} 3$ of soil. Plant growth was determined by measuring plant height, stem diameter, number of leaves and water consumption throughout the cycle, and dry mass of roots, stem and leaf at the time of collection of the experiment. For statistical analysis of the data, analysis of variance, Tukey average test and regression analysis were performed. In general, the growth characteristics of the plants showed a more pronounced response to phosphate fertilization compared to the physical compression tested. Jatropha roots were unable to penetrate a soil layer with a specific gravity of $1.91 \mathrm{~kg} \mathrm{dm}-3$.

\section{Keywords:}

Jatropha curcas L. Water consumption. Plant biometrics. Phosphate fertilization. Soil compressibility.

\section{Como você deve citar?}

CASTRO, Jair Henrique de et al. Crescimento do pinhão-manso em resposta à adubação fosfatada e à compactação de um Latossolo Vermelho Amarelo sob cultivo em ambiente protegido. Cadernos UniFOA, Volta Redonda, n. 45, p. 07-21, abril 2021. 
Crescimento do pinhão-manso em resposta à adubação fosfatada e à compactação de um Latossolo Vermelho Amarelo sob cultivo em ambiente protegido

\section{INTRODUÇÃO}

O pinhão-manso (Jatropha curcas L.) é uma planta capaz de acumular de 30 a $40 \%$ de óleo em suas sementes, sendo assim uma alternativa à matriz bioenergética brasileira. É também recomendado para recuperação de solos compactados, dado à rusticidade de suas raízes, capaz de romper impedimentos físicos causados por "pé de grade" (SATURNINO et al., 2005).

A compactação de solo é definida como o método capaz de aumentar mecanicamente a densidade do solo. É uma das principais fontes de degradação do solo, pois diminui a infiltração de água e impede o aprofundamento radicular, fatos que conjuntamente prejudicam o desenvolvimento e a produção das culturas. Ao desfavorecer a infiltração de água no solo, a compactação potencializa perda de água, de solo e de nutrientes por escoamento superficial, contribuindo para o aumento da erosão de natureza hídrica, com diminuição, principalmente, de argila e matéria orgânica, diminuindo assim, a sua fertilidade (JORGE, 1983).

Normalmente, o fósforo $(\mathrm{P})$ é o nutriente mais afetado pelo grau de compactação de um solo, havendo menor disponibilidade desse nutriente com a elevação da compactação. $O$ transporte de $P$, ou seja, a sua migração da partícula de solo até um pelo radicular absorvente, ocorre principalmente por difusão, processo em que o elemento químico migra em um filme de água, estando sujeito à fixação pelo solo (MALAVOLTA, 2006). A compactação do solo, ao diminuir o teor de água e ao aumentar a tortuosidade do caminhamento do nutriente até a raiz, potencializa essa fixação de $\mathrm{P}$, ocasionando déficit nutricional na planta, com prejuízo no desenvolvimento e produtividade, inclusive aumentando a possibilidade de ocorrência de déficit hídrico, uma vez que diminui a infiltração e o armazenamento de água no solo (BERTONI; LOMBARDI NETO, 1999).

Os recentes estudos com pinhão-manso, visando desenvolver um sistema de produção confiável para a cultura, desmistificaram a propalada rusticidade dessa planta, pois é muito atacada por pragas e doenças e possui elevada exigência nutricional com acentuado acúmulo de minerais em suas partes vegetativas e reprodutivas (SATURNINO et al., 2005; CARVALHO et al., 2013; SILVA et al., 2015; LINHARES et al., 2016). O pinhão-manso é uma cultura com poucas pesquisas sobre seu comportamento em campo e o conhecimento técnico sobre essa cultura no norte de Minas Gerais ainda é limitado.

Tendo os fatores compactação e P - dois importantes gargalos em sistemas convencionais de preparo do solo - o presente trabalho objetivou determinar o crescimento e o consumo hídrico de pinhão-manso em resposta à compactação de solo e doses de $P$.

\section{MATERIAL E MÉTODOS}

O experimento foi conduzido no setor de fruticultura no Instituto Federal de Educação, Ciência e Tecnologia do Norte de Minas - campus Januária, Fazenda São Geraldo, município de Januária, MG, com as seguintes coordenadas geográficas: Latitude: $15^{\circ} 26^{\prime} \mathrm{S}$, Longitude: $44^{\circ} 22^{\prime} \mathrm{W}$, e altitude de $474 \mathrm{~m}$. A região apresenta temperatura média anual de $24,4 \mathrm{C}$, umidade relativa média de $60 \%$ e precipitação média anual de $814 \mathrm{~mm}$ (Oliveira et al., 2020). As dimensões da estufa eram 3,00 m de "pé-direito"; 4,00 m de altura no vão central; $25 \mathrm{~m}$ de comprimento e $6 \mathrm{~m}$ de largura. A cobertura superior consistia em sombrite malha $60 \%$ e na lateral havia tela zincada. As bancadas onde foram dispostas as unidades experimentais ficavam a uma altura de 0,6 m do solo, sendo constituídas de ripado, abrangendo uma largura de 1,3 m.

Para aplicação dos tratamentos, utilizou-se amostra de solo Latossolo Vermelho Amarelo, coletado na camada de $20-40 \mathrm{~cm}$ de profundidade, em área tradicionalmente cultivada com sorgo em regime 
convencional de preparo de solo com gradagem, tendo-se o cuidado de se utilizar um solo com baixa disponibilidade de $\mathrm{P}\left(1,4 \mathrm{mg} \mathrm{dm}^{-3}\right.$ de $\left.\mathrm{P}\right)$. A massa específica inicial de solo, determinada pelo método do anel volumétrico (EMBRAPA, 1997), era de $1,77 \mathrm{mg} \mathrm{dm}^{-3}$. As demais características físico-químicas do solo encontram-se listadas na Tabela 1.

Tabela 1 - Caracterização físico-química de amostra de solo coletada na camada de $20-40 \mathrm{~cm}$ de profundidade

\begin{tabular}{|c|c|c|c|c|c|c|c|c|c|c|c|c|c|c|}
\hline \multirow[b]{2}{*}{$\mathrm{pH}$} & \multicolumn{9}{|c|}{ Composição Química } & \multicolumn{5}{|c|}{ Comp Física } \\
\hline & MO & $\mathrm{P}$ & $\mathrm{K}$ & $\mathrm{Ca}$ & $\mathrm{Mg}$ & Al & $\mathrm{H}+\mathrm{Al}$ & $\mathrm{Cu}$ & $\mathrm{Fe}$ & $\mathrm{Mn}$ & $\mathrm{Zn}$ & Areia & Silte & Argila \\
\hline & dag $\mathrm{kg}^{-1}$ & \multicolumn{2}{|c|}{$\mathrm{mg} \mathrm{dm}^{-3}$} & \multicolumn{3}{|c|}{$\mathrm{cmol}_{c} \mathrm{dm}^{-3}$} & & \multicolumn{2}{|c|}{$\mathrm{mg} \mathrm{dm}^{-3}$} & \multicolumn{5}{|c|}{ dag kg-1 } \\
\hline 4,8 & 0,1 & 1,4 & 14 & 0,0 & 0,0 & 0,3 & 1,5 & 0,1 & 7,0 & 8,3 & 0,9 & 76 & 9 & 15 \\
\hline
\end{tabular}

Fonte: Os Autores (2020)

Os nove tratamentos foram definidos pela combinação dos fatores compressibilidade de solo e doses de $\mathrm{P}$, cada qual com três níveis, distribuídos em um fatorial completo e em delineamento em blocos casualizados, sendo três o número de repetições, totalizando 27 parcelas experimentais. Para aplicação desses tratamentos, inicialmente o solo foi secado à sombra e depois tamisado em peneira com malha de $4 \mathrm{~mm}$. Em seguida, foram feitas nove medidas com 9,062; 9,810 e 10,560 kg de solo. Procedeu-se à incubação dos solos, aplicando-se a cada uma das medidas anteriores as quantidades de $3,84 \mathrm{~g}$ de calcário ( $25 \%$ de Si; $54 \%$ de Ca; $12 \%$ de Mg; $98 \%$ de reatividade e $113 \%$ de PRNT); $3,142 \mathrm{~g}$ de sulfato de amônio; $1,958 \mathrm{~g}$ de cloreto de potássio; $5,584 \mathrm{~g}$ de sulfato de magnésio; $0,0370 \mathrm{~g}$ de ácido bórico; $0,157 \mathrm{~g}$ de sulfato de zinco; $0,003 \mathrm{~g}$ de molibdato de amônio. As doses aplicadas de $\mathrm{P}$ foram de $0 ; 7,994$ e $23,983 \mathrm{~g}$ de superfosfato simples $\left(18 \%\right.$ de $\left.\mathrm{P}_{2} \mathrm{O}_{5}\right)$. As quantidades de água utilizadas para incubação foram de 2.809, 3.040 e $3.276 \mathrm{~mL}$, aplicadas, respectivamente, às massas de 9,062; 9,810 e $10,560 \mathrm{~kg}$ de solo, propiciando umidade igual a $31 \%$. 0 processo de incubação durou 15 dias, a fim de estabilizar as reações químicas decorrente da aplicação dos fertilizantes.

Para aplicação das unidades experimentais, foram utilizados vasos de PVC com 19,4 cm de diâmetro interno e $23,5 \mathrm{~cm}$ de altura, vedando-se a base do vaso com madeira de pinus $(2,5 \mathrm{~cm}$ de espessura), a qual foi impermeabilizada com plástico autoadesivo. Ao desconsiderar $1 \mathrm{~cm}$ de borda superior, cada vaso tinha volume útil igual a $5,912 \mathrm{dm}^{3}$, os quais foram preenchidos com a massa de solo correspondente a cada tratamento referentes a nove possíveis combinações dos fatores massa específica de solo e doses de P. Na lateral inferior dos vasos, foram feitos quatro furos, posicionados em formato de cruz, onde foram inseridos microtubos de $5 \mathrm{~mm}$ de diâmetro, que funcionaram como drenos.

As amostras de solo, posterior à fase de incubação, foram colocadas nos vasos, divididas em três camadas de iguais alturas. Às duas camadas inferiores foram aplicadas compressões físicas, a fim de permitir massas específicas de solo iguais a 1,53; 1,72 e 1,91 $\mathrm{kg} \mathrm{dm}^{-3}$, ao passo que, na camada superior, utilizou-se a massa específica de $1,53 \mathrm{~kg} \mathrm{dm}^{-3}$ de solo comum a todos os tratamentos, a fim de permitir a formação e crescimento inicial do sistema radicular da planta. Para fins de compressão física, utilizou-se um soquete tipo macete, com massa de 1,030 kg e superfície de exposição igual a $4275 \mathrm{~mm}^{2}(71,54 \times 59,78 \mathrm{~mm})$. Para esse fim, restabeleceu-se a umidade das amostras de solo igual àquela do início do processo de incubação.

Os nove tratamentos $-0,106$ e $318 \mathrm{mg} \mathrm{dm}^{-3}$ de $\mathrm{P}$ fatorialmente combinados às massas específicas de 1,53, 1,72 e 1,91 kg dm${ }^{-3}$ de solo - consideraram um vaso por parcela. Nas bancadas, os vasos foram orientados em três fileiras, distanciando-se $20 \mathrm{~cm}$ da fileira central em relação às das extremidades, obedecendo-se ao mesmo espaçamento entre vasos dentro da fileira. Foram semeadas três sementes de pinhão-manso por vaso, a uma profundidade de $3 \mathrm{~cm}$, em 29 de março de 2008. As 
Crescimento do pinhão-manso em resposta à adubação fosfatada e à compactação de um Latossolo Vermelho Amarelo sob cultivo em ambiente protegido

sementes foram extraídas de uma planta matriz pertencente a uma unidade demonstrativa de pinhão-manso localizada no IFNMG, Campus Januária. As plantas emergiram sete dias pós-semeio (DPS) e procedeu-se o desbaste aos 15 DPS, permitindo o crescimento da planta mais vigorosa em cada vaso.

Os tratos culturais consistiram de catação manual de pragas, de rara ocorrência, de uma escarificação de solo aos 30 DPS, a fim de se prevenir o crescimento de algas e de facilitar a infiltração de água e de irrigações periódicas, de acordo com as necessidades hídricas das plantas, utilizando-se água de chuva armazenada em caixa d'água de $2.000 \mathrm{~L}$ (Tabela 2), sendo classificada como de baixo risco de salinização.

Tabela 2 - Caracterização química da água utilizada para irrigação do experimento

\begin{tabular}{|c|c|c|c|c|c|c|c|c|}
\hline \multicolumn{9}{|c|}{ Composição química } \\
\hline $\mathrm{pH}$ & CE & $\mathrm{Ca}$ & $\mathrm{Mg}$ & K & $\mathrm{Na}$ & $\mathrm{CO}_{3}{ }^{2-}$ & $\mathrm{HCO}_{3}^{-}$ & $\mathrm{Cl}^{-}$ \\
\hline &.$\mu m h o s \mathrm{~cm}^{-1} 25^{\circ} \mathrm{C}$. & & & & $\mathrm{cmol}_{C} \mathrm{C}$ & & & \\
\hline 6,9 & 29 & 0,07 & 0,00 & 0,04 & 0,08 & 0,00 & 0,04 & 1,20 \\
\hline
\end{tabular}

O crescimento das plantas foi monitorado a partir de medidas de altura, diâmetro do caule rente ao solo e número de folhas emitidas ao longo do ciclo. As folhas senescentes foram colhidas ao longo da condução do experimento. A irrigação foi feita diariamente, aplicando-se volume conhecido de água, medido com proveta, a fim de se manter umidade de solo satisfatória ao crescimento das plantas.

A coleta do experimento ocorreu aos 123 DPS. As plantas foram fracionadas em folhas aderidas ao caule, folhas senescentes (incluindo aquelas colhidas ao longo da condução do experimento), caule e raízes, quantificando-se, em balança analítica, a biomassa acumulada em cada um desses órgãos.

Para avaliação das raízes, a coluna de solo no vaso foi estratificada em três camadas de igual altura, coletando-se nelas todas as raízes de fácil visualização, incluindo a pivotante e âncoras. Para a estimativa de massas de raízes mais finas, trabalhou-se com uma amostragem constituída de $20 \%$ da fração do solo, coletando-se nesse volume o máximo possível de raízes. A massa fresca total de raízes foi calculada, considerando-se a soma das raízes de fácil visualização e raízes finas multiplicada por cinco vezes. Para determinar a massa total da planta, foram consideradas as quantidades acumuladas de massa seca de caule, folhas aderidas ao caule, folhas senescentes e raízes totais.

Os dados de crescimento - altura, diâmetro de colo e número de folhas; e medida de biomassa de folhas, caule e raízes - foram submetidos à análise de variância, teste de média Tukey a $5 \%$ de probabilidade e análise de regressão, com auxílio do software ASSISTAT 7.5 beta (SILVA, 2008), considerando-os como variáveis dependentes das épocas de amostragens de plantas, doses de P e graus de compressibilidade aplicadas ao solo.

\section{RESULTADOS E DISCUSSÃO}

A altura, o diâmetro de colo e o número de folhas de pinhão-manso foram significativamente menores nas plantas não adubadas com P (Tabela 3). Resultados semelhantes foram encontrados por Freiberger et al. (2014), em que a diferença desses tratamentos não adubados com $P$ em relação aos adubados ficou mais pronunciada a partir dos 60 dias após o transplantio. Não houve diferenças

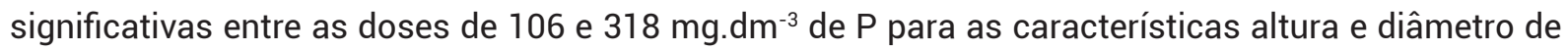
colo, enquanto, na maior dose de P, as plantas possuíram mais folhas. Firmino et al. (2015) observaram 
efeito significativo para o fator doses de fósforo apenas aos 276 DAP. No entanto, Costa et al. (2009) encontraram diferenças significativas entre as doses de fósforo (0; 50; 100; 150 e $\left.200 \mathrm{~g} \mathrm{planta}^{-1}\right)$ em pinhão-manso, a partir dos 60 dias após o transplantio.

Tabela 3 - Altura, diâmetro de colo e número de folhas de pinhão-manso, à época de coleta de plantas, em resposta as doses de $\mathrm{P}$ e compressibilidade de solo.

\begin{tabular}{cccc}
\hline $\mathbf{P}$ & Altura & Diâmetro & Número de folhas \\
\hline $\mathrm{mg} \mathrm{dm}^{-3}$ & \multicolumn{3}{c}{$\mathrm{cm}$} \\
\hline 0 & $17,68 \mathrm{~B}$ & $18,15 \mathrm{~B}$ & $3,83 \mathrm{C}$ \\
\hline 106 & $22,25 \mathrm{~A}$ & $26,05 \mathrm{~A}$ & $12,83 \mathrm{~B}$ \\
\hline 318 & $23,75 \mathrm{~A}$ & $27,36 \mathrm{~A}$ & $14,67 \mathrm{~A}$ \\
\hline $\boldsymbol{\rho} \mathbf{c}$ & Altura & Diâmetro & Número de folhas \\
\hline $\mathrm{kg} \mathrm{dm}^{-3}$ & \multicolumn{5}{c}{$\mathrm{cm}$} & \\
\hline 1,53 & $21,17 \mathrm{AB}$ & $24,50 \mathrm{~A}$ & $12,66 \mathrm{~A}$ \\
\hline 1,72 & $22,35 \mathrm{~A}$ & $23,53 \mathrm{~A}$ & $9,83 \mathrm{~B}$ \\
\hline 1,91 & $20,17 \mathrm{~B}$ & $23,53 \mathrm{~A}$ & $8,83 \mathrm{~B}$ \\
\hline
\end{tabular}

*, médias seguidas por mesma letra na coluna não diferem entre si pelo teste Tukey ao nível de $5 \%$ de probabilidade.

Fonte: Os Autores (2020)

As plantas de pinhão-manso submetidas às massas específicas de solo iguais a 1,53; 1,72 e 1,91 $\mathrm{kg} \mathrm{dm}^{-3}$ apresentaram altura significativamente influenciada pelas épocas de avaliações nas diferentes doses de P (Figura 1). Semelhante comportamento também ocorreu para as características diâmetro de colo e número de folhas (Figuras 2 e 3). De maneira geral, as plantas atingiram maior altura, maior diâmetro de colo e maior número de folhas, quando submetidas às doses de 106 e $318 \mathrm{mg} \mathrm{dm}^{-3} \mathrm{de} \mathrm{P}$, se comparadas àquelas crescidas com omissão da adubação fosfatada. Esses resultados corroboram com o trabalho desenvolvido por Ohland et al. (2014), em que o desenvolvimento do sistema radicular, parte aérea e o conteúdo de $\mathrm{P}$ e $\mathrm{K}$ nas plantas de pinhão-manso reduziram-se linearmente com o aumento da densidade do solo em todas as épocas avaliadas.

Quanto ao efeito da massa específica de solo, as plantas submetidas a 1,91 $\mathrm{kg} \mathrm{dm}^{-3}$, na maioria das doses de $\mathrm{P}$, apresentaram menores valores para as mencionadas características em comparação às condições de 1,53 e 1,72 kg dm${ }^{-3}$, demonstrando o prejuízo da compressibilidade do solo sobre o crescimento das plantas. Resultados semelhantes foram obtidos por Ohland et al. (2014), em que o aumento da densidade do solo, de 1,08 a $1,64 \mathrm{~kg} \mathrm{dm}^{-3}$, influenciou negativamente as variáveis número de folhas, área foliar e altura de plantas. Kato (2012) afirma que densidade do solo acima de 1,25 é prejudicial para o crescimento da cultura.

De acordo com Santos et al. (2012), a resposta das plantas de pinhão-manso à variação de densidade no solo pode estar relacionada à pequena quantidade de raízes que chegaram às camadas mais compactadas e pode ser atribuída ao fato de as raízes não conseguirem se recuperar do estresse ao qual estão submetidas.

De acordo com esses resultados, pode-se inferir que plantas de pinhão-manso se desenvolvem melhor em solos que não apresentam limitação ao crescimento radicular, com baixos valores de densidades, porém, com densidade suficiente para oferecerem bom contato entre raízes e partículas de solo, e promover além de uma boa aeração, a absorção dos nutrientes pelas plantas. 
Figura 1 - Curva de resposta de altura de pinhão-manso submetido à massa específica de solo igual a 1,53 (•), 1,72(•) e 1,91 kg dm${ }^{-3}(\cdot)$, adubado com 0; 106 e $318 \mathrm{mg} \mathrm{dm}^{-3}$, em função de dias pós-emergência.
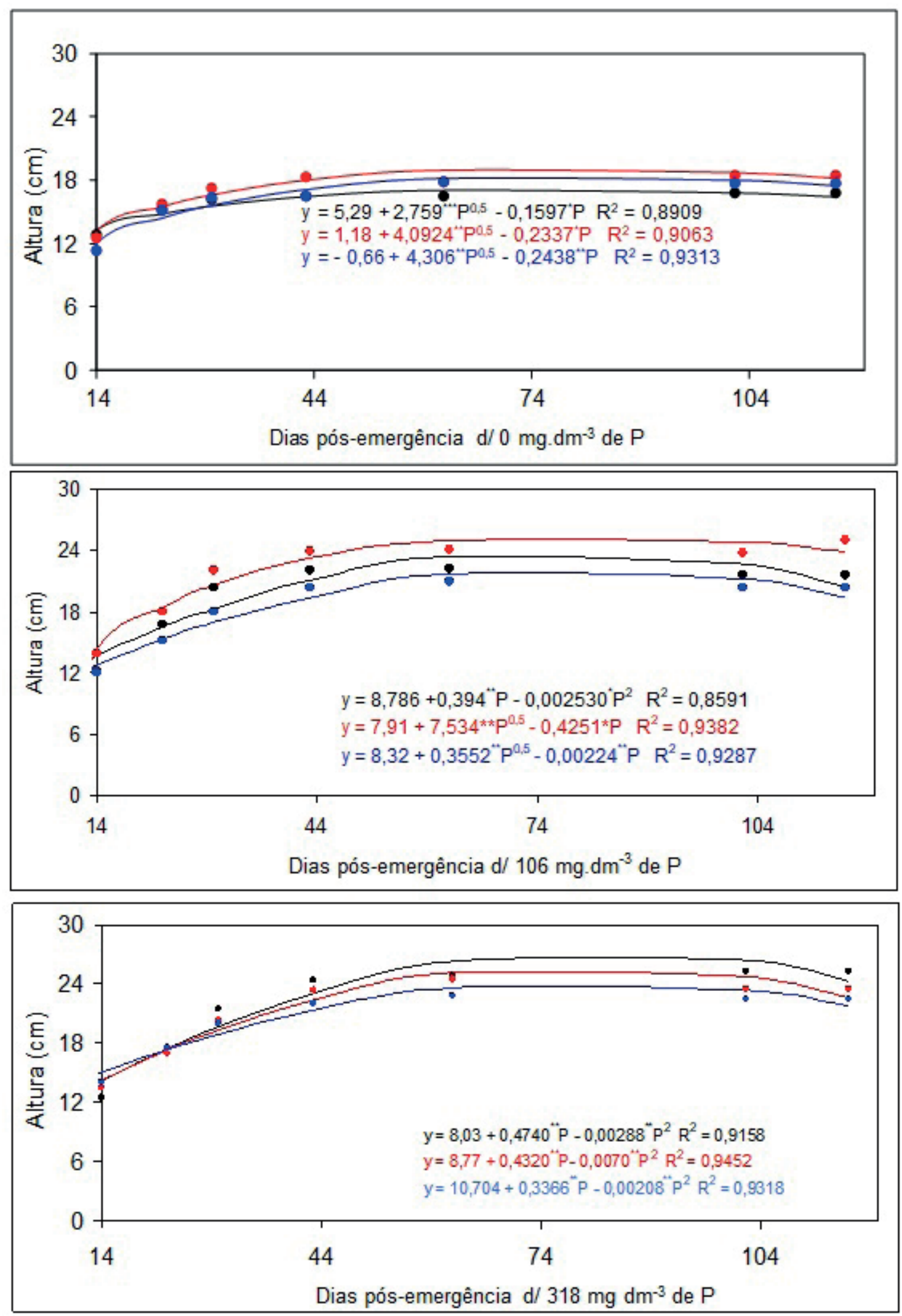

Fonte: Os Autores (2020) 
Figura 2 - Curva de resposta de diâmetro de colo de pinhão-manso submetido à massa específica de solo igual a 1,53 (•), 1,72(•) e 1,91 kg dm${ }^{-3}(\cdot)$, adubado com 0,106 e $318 \mathrm{mg} \mathrm{dm}^{-3}$, em função de dias pós-emergência.
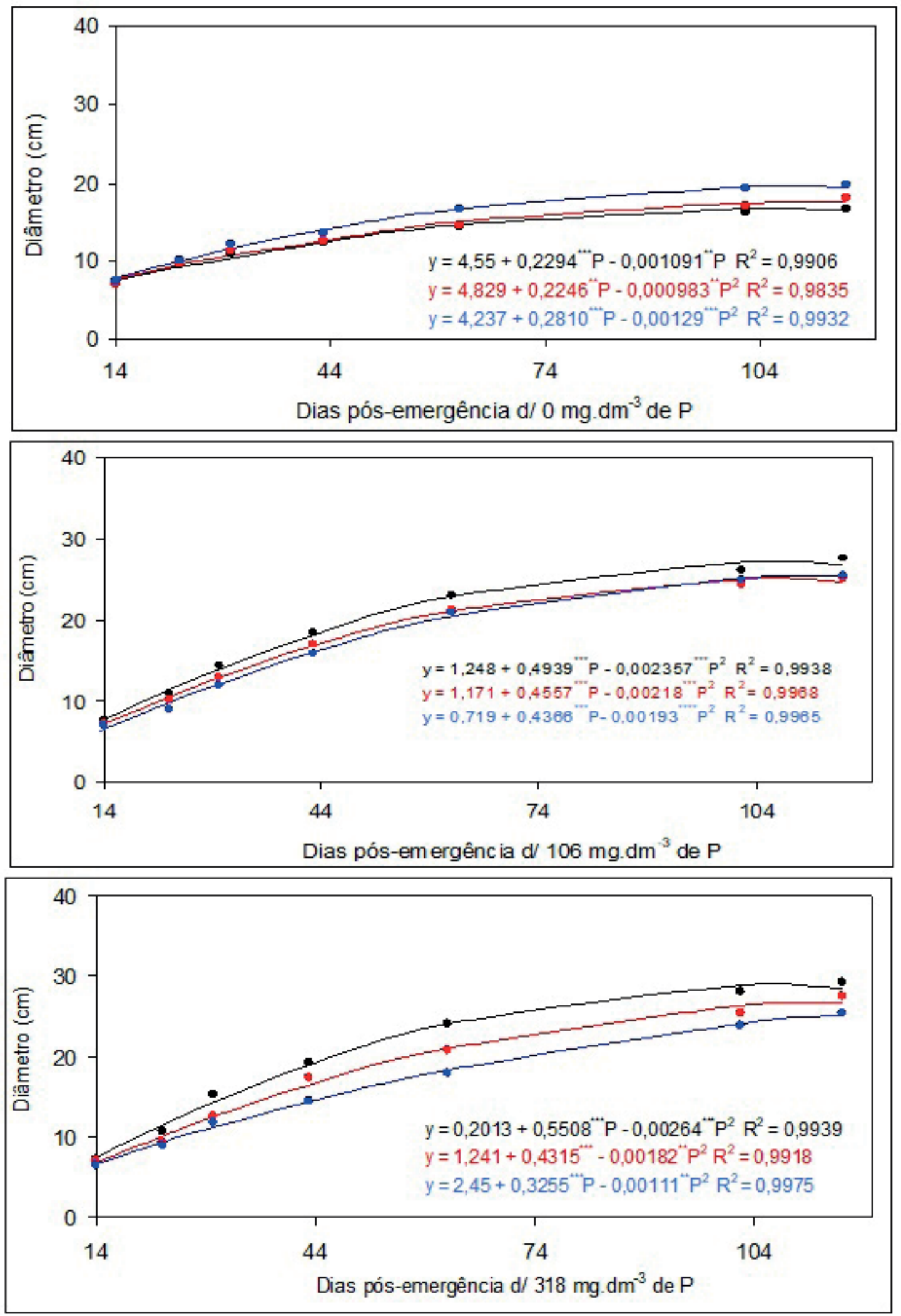

Fonte: Os Autores (2020) 
Crescimento do pinhão-manso em resposta à adubação fosfatada e à compactação de um Latossolo Vermelho Amarelo sob cultivo em ambiente protegido

Figura 3 - Curva de resposta para número de folhas de pinhão-manso submetido à massa específica de solo igual a $1,53(\cdot), 1,72(\cdot)$ e 1,91 $\mathrm{kg} \mathrm{dm}^{-3}(\cdot)$, adubado com 0, 106 e $318 \mathrm{mg} \mathrm{dm}^{-3}$, em função de dias pós-emergência.
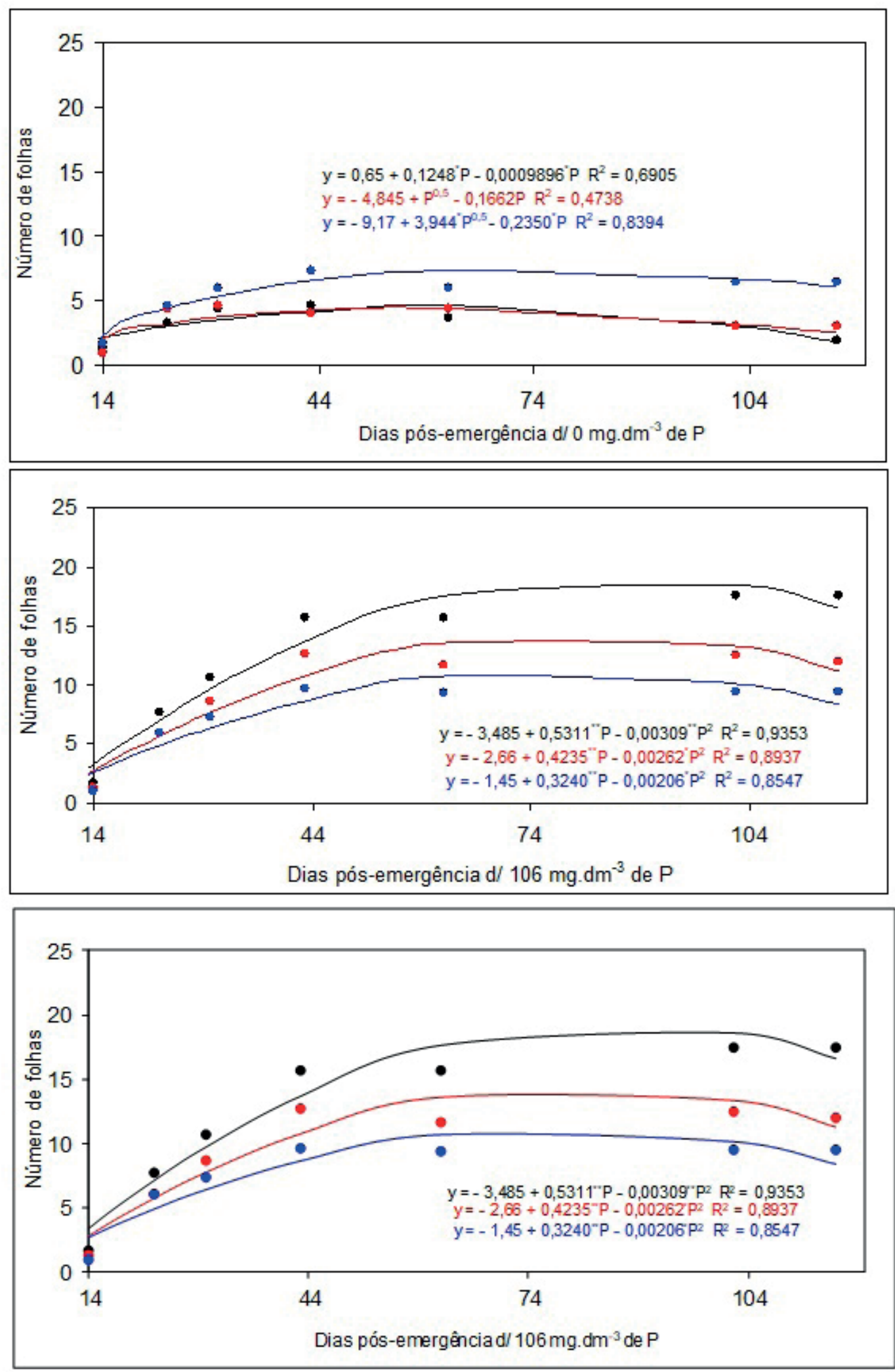

Fonte: Os Autores (2020) 
As massas secas de raízes finas distribuídas nas camadas de 0-6,66; 6,67-13,32 e de 13,33-20 $\mathrm{cm}$ responderam de modo variado às doses de $\mathrm{P}$ e às massas específicas dos solos (Figura 4). Enquanto na camada superior de solo a resposta ocorreu de modo linear às doses de $P$, na camada inferior a resposta foi quadrática à massa específica do solo, não se constatando crescimento de raízes nas plantas sujeitas a $1,91 \mathrm{~kg} \mathrm{dm}^{-3}$ (Foto 3). Na camada intermediária, a massa de raiz respondeu simultaneamente às doses de $\mathrm{P}$ e às massas específicas do solo, linear positiva ao primeiro e quadrática ao segundo fator.

Figura 4 - Massa seca de raízes finas de pinhão-manso desenvolvidas nas camadas de 0 a 6,66; de 6,67 a 13,33 e 13,34 a 20,0 cm de profundidade em resposta às doses de $\mathrm{P}$ e massas específicas de solo.
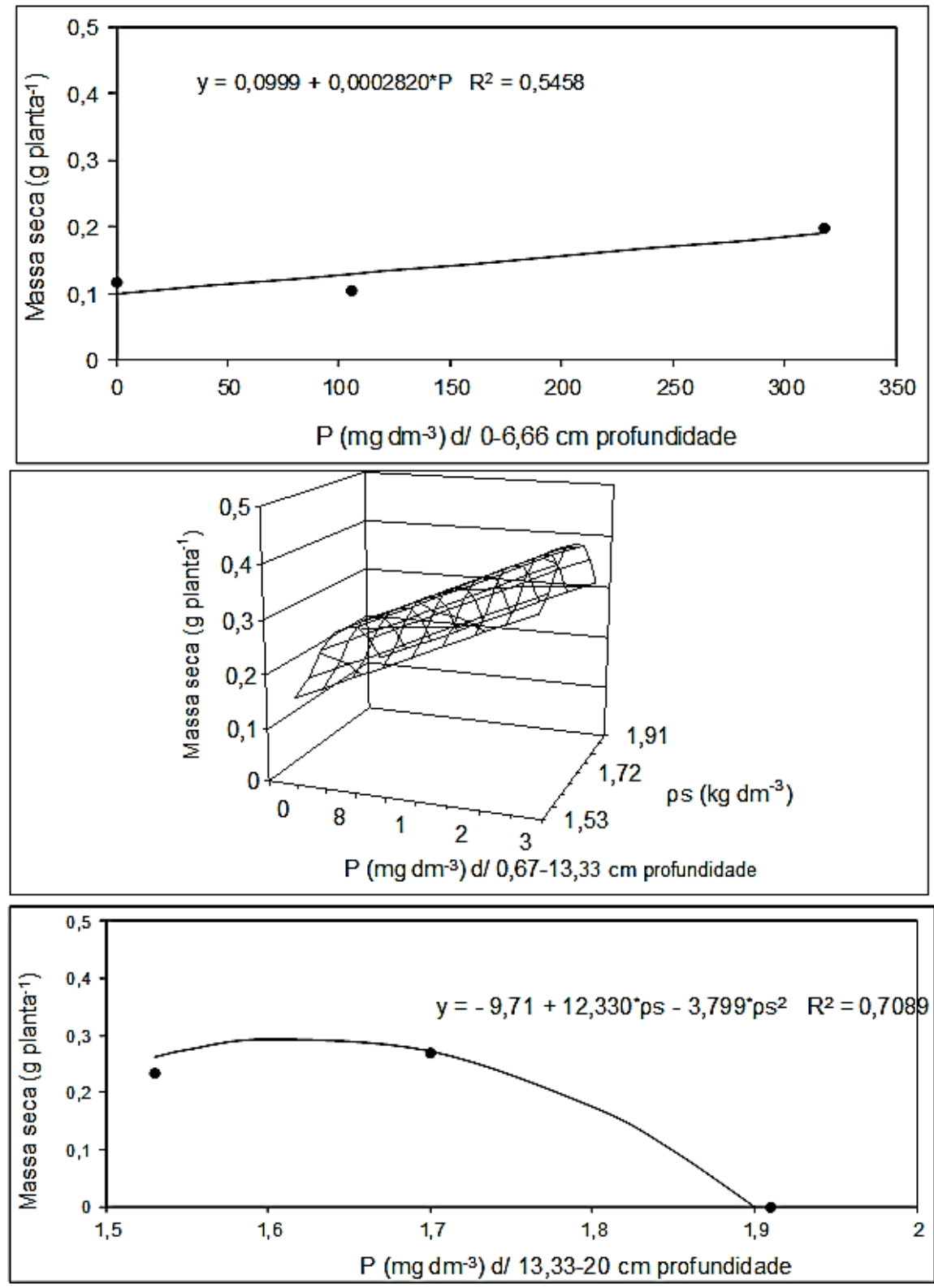

Fonte: Os Autores (2020) 
Foto 1 - Distribuição radicular de plantas de pinhão-manso na camada de 0 a 6,66 cm de profundidade de solo, evidenciando a tortuosidade da raiz pivotante aos $6,67 \mathrm{~cm}$ de profundidade, limite inicial da camada de solo com massa específica igual a $1,91 \mathrm{~kg} \mathrm{dm}^{-3}$.
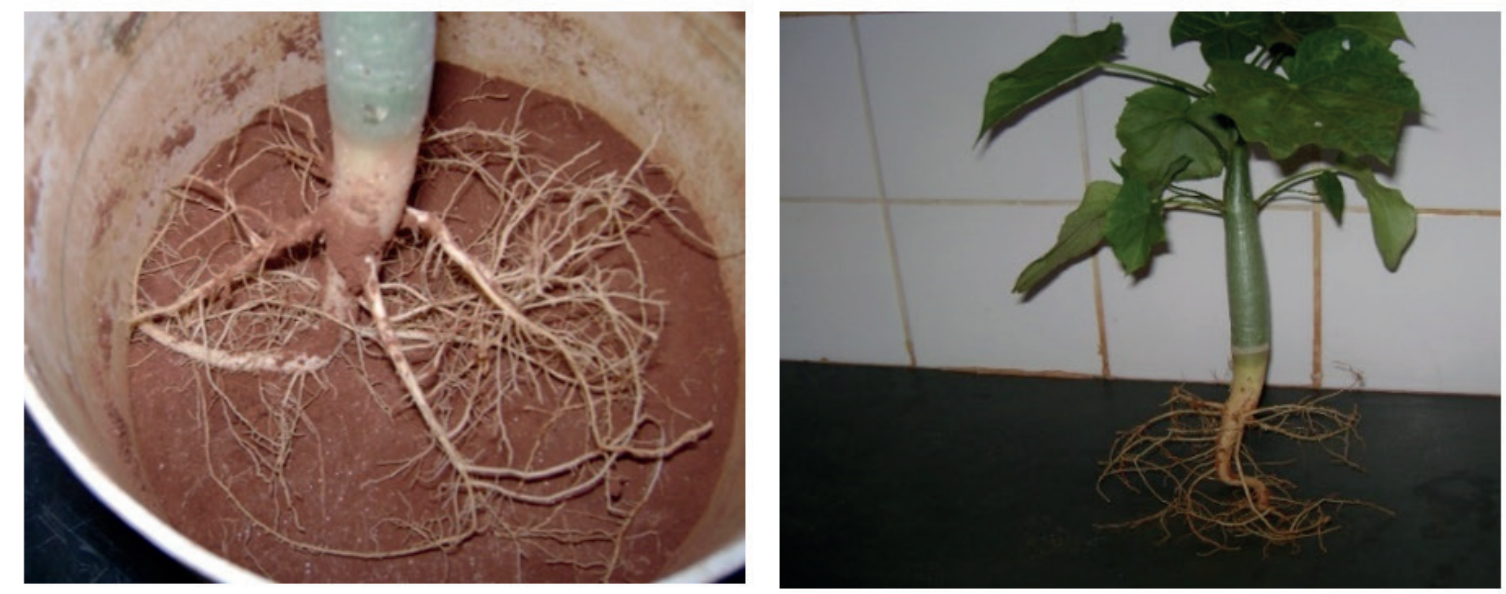

Fonte: Os Autores (2020)

As massas secas de raízes grossas e de raízes totais responderam linearmente às doses de $\mathrm{P}$ (Figuras 5 e 6). Comparando-se as magnitudes dos valores à massa seca de raízes finas, a massa dessa última foi menor, visto que as quantidades de raízes grossas e totais apresentaram valores aproximados. 0 acúmulo de significativa quantidade de massa seca de raízes mais grossas era esperado por sua função cumulativa de reserva energética da planta. Justifica-se a menor massa seca de raízes mais finas ao fato de elas relacionarem fundamentalmente com os processos de absorção de água e nutrientes, sendo, portanto, de mais rápida síntese e degradação, o que dificulta efeitos cumulativos para sua biomassa. Resultados similares também foram encontrados por Ohland et al. (2014), em que o comprimento e o volume radicular, a produção de matéria seca de raiz e a relação raiz/parte aérea apresentaram comportamento linear, decrescendo com o aumento da densidade do solo.

Figura 5 - Massa seca de raízes grossas em resposta às doses de $P$.

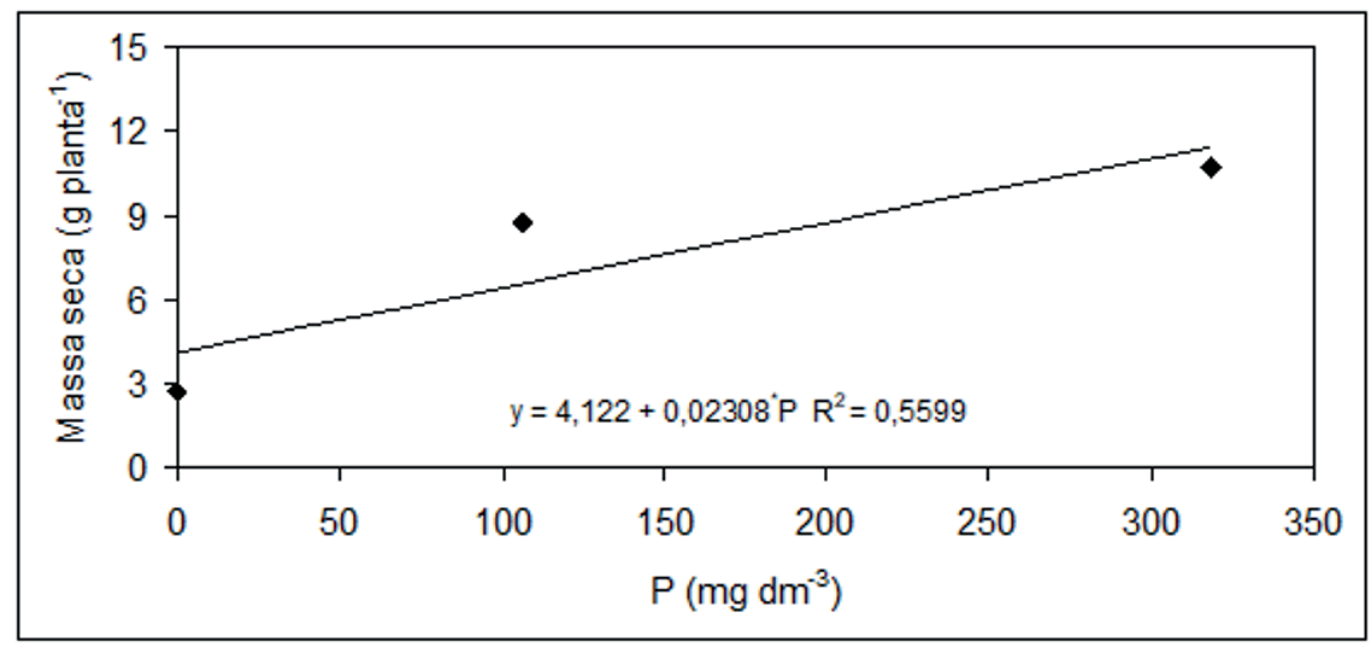

Fonte: Os Autores (2020) 
Figura 6 - Massa seca de raízes totais de pinhão-manso em resposta às doses de $\mathrm{P}$.

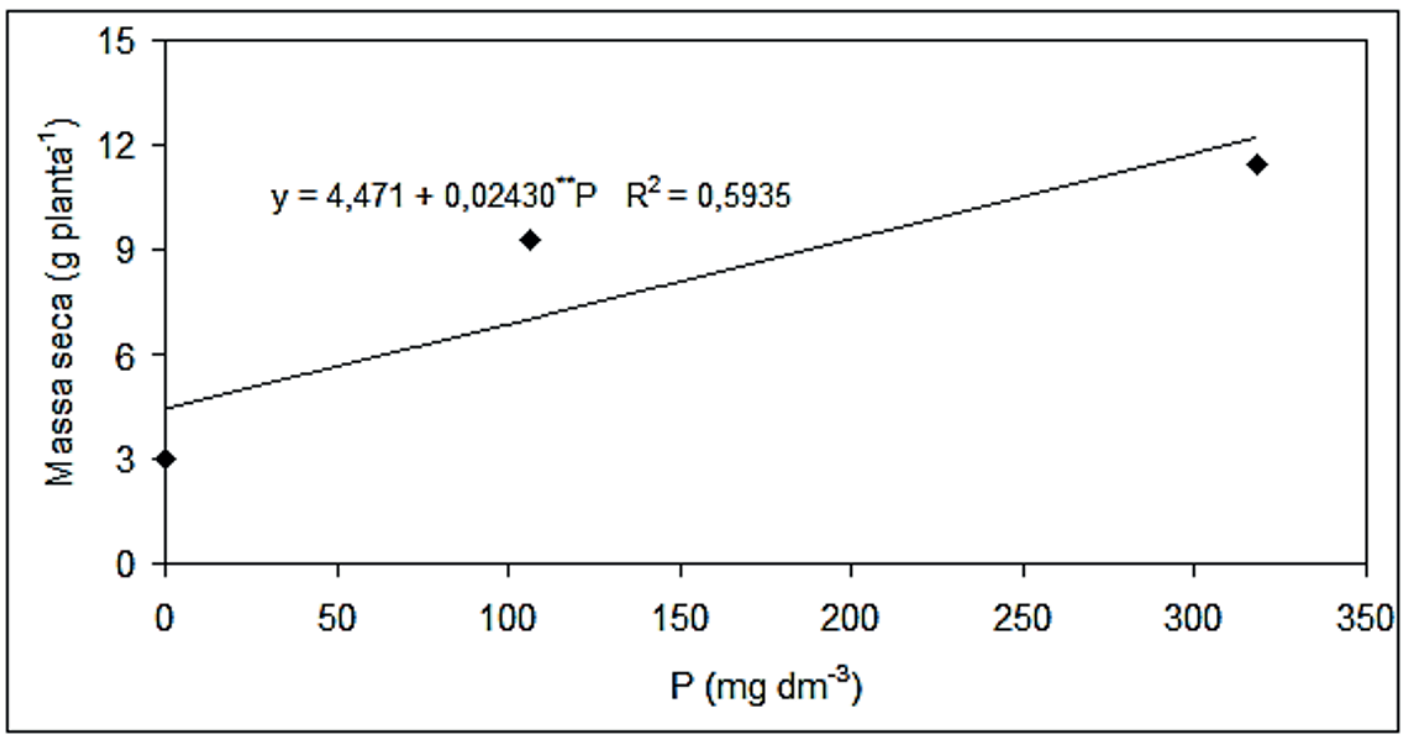

Fonte: Os Autores (2020)

O pinhão-manso apresentou massa seca de caule com resposta quadrática às doses de $\mathrm{P}$ (Figura 7), sendo este o órgão que mais se destacou quanto ao acúmulo de biomassa. A máxima massa seca de caule correspondeu a 15,8 g planta-1, estimada nas plantas cultivadas com $246,72 \mathrm{mg} \mathrm{dm}^{-3} \mathrm{de} \mathrm{P}$. Nessa dose de $P$, a quantidade de massa seca de caule superou aquelas determinadas para raízes nas categorias de raízes finas, grossas e totais.

Figura 7 - Massa seca de caule de pinhão-manso em resposta às doses de P.

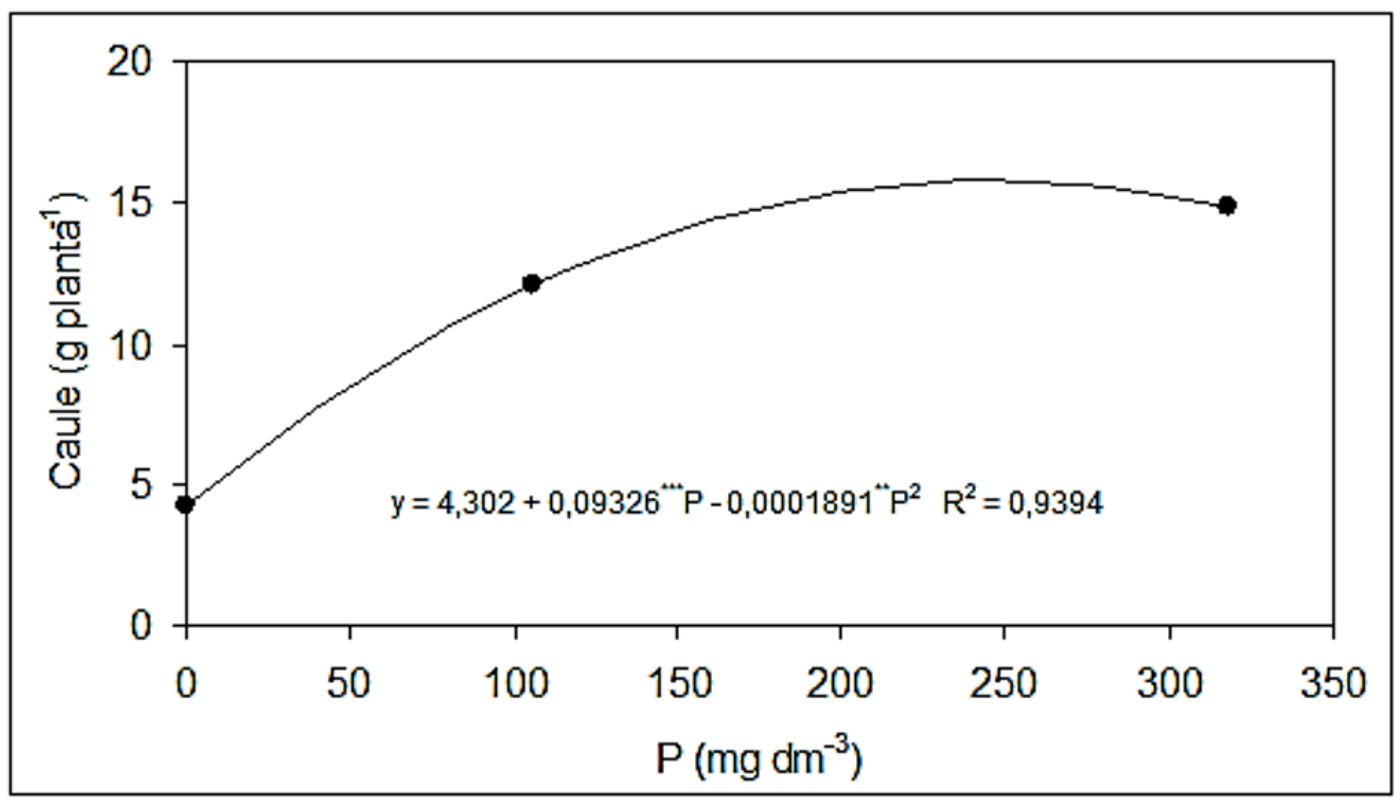

Fonte: Os Autores (2020) 
Crescimento do pinhão-manso em resposta à adubação fosfatada e à compactação de um Latossolo Vermelho Amarelo sob cultivo em ambiente protegido

As massas secas das folhas aderidas às plantas e das folhas senescentes apresentaram, respectivamente, resposta quadrática e linear às doses de $\mathrm{P}$ (Figura 8). Entre essas características, a massa das folhas senescentes foi sempre inferior para todas as situações estudadas, principalmente, quando se aplicou o adubo fosfatado. Mesmo somadas, verificou-se que a massa seca dessas folhas foi bastante inferior aos valores estimados para raízes e caule.

As plantas de pinhão-manso tiveram a massa seca total significativamente influenciada pelas doses de $\mathrm{P}$ (Figura 9). A massa seca total da planta atingiu o máximo valor de $33,41 \mathrm{~g} \mathrm{planta}^{-1}$, sendo isso estabelecido na dose de $253,15 \mathrm{mg} \mathrm{dm}^{-3} \mathrm{de} P$.

Figura 8 - Massa seca de folhas aderidas ao caule $(\cdot)$ e de folhas senescentes $(\cdot)$ de pinhão-manso em resposta às doses de $P$.

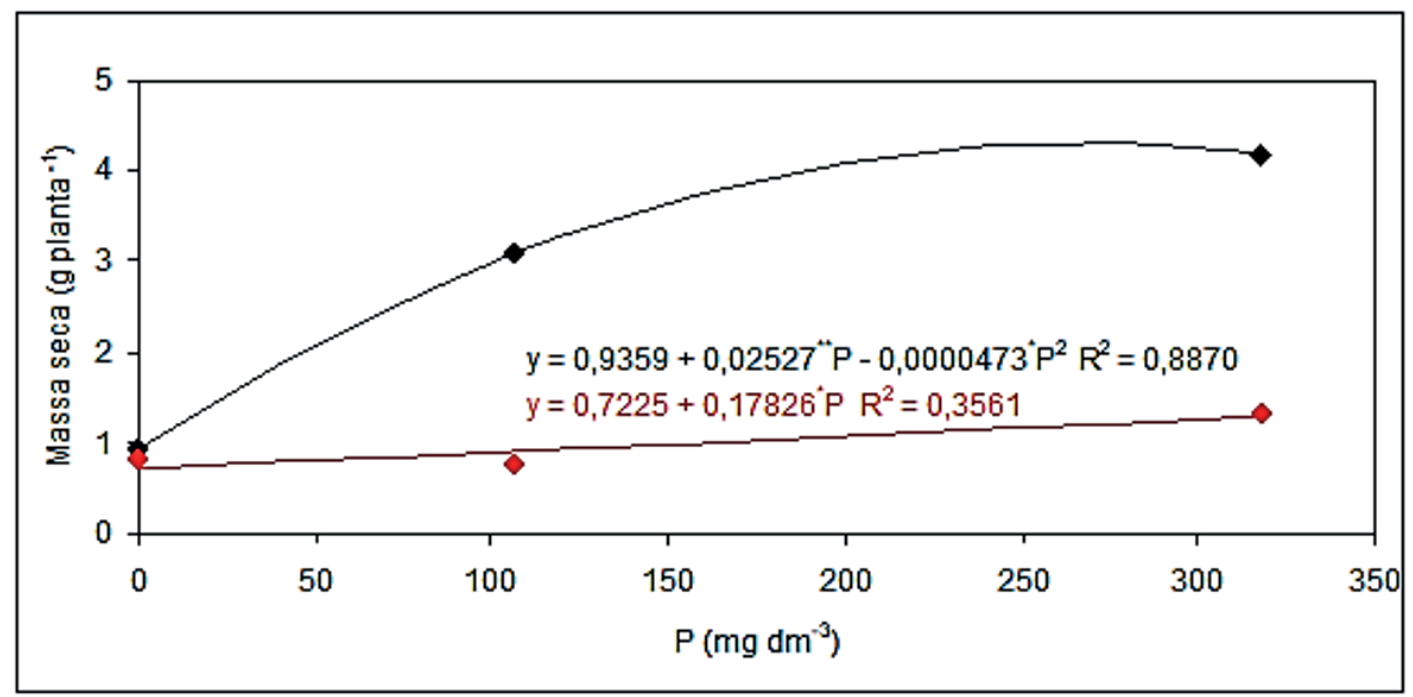

Fonte: Os Autores (2020)

Figura 9 - Massa seca total de pinhão-manso em resposta às doses de $P$.

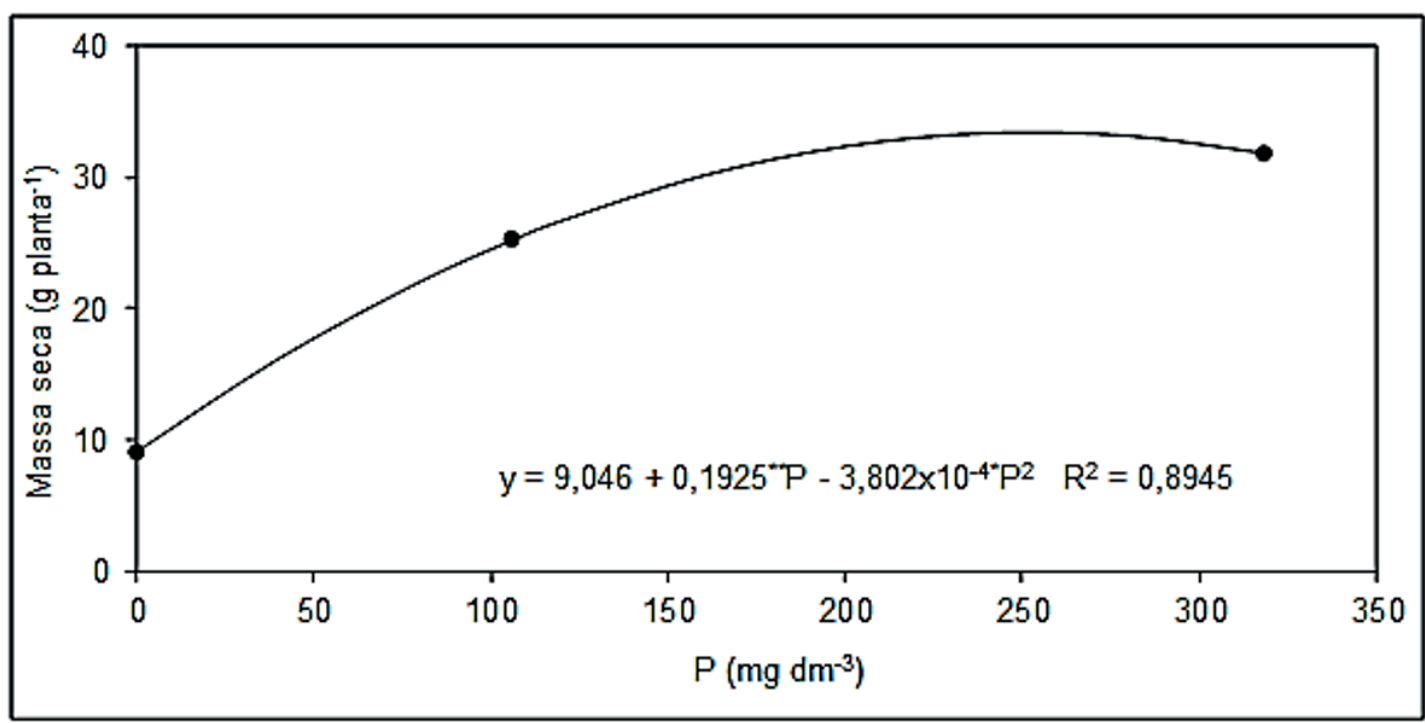

Fonte: Os Autores (2020) 
O consumo de água durante o crescimento das plantas de pinhão-manso apresentou resposta quadrática às doses de $P$, não sendo influenciada pelas massas específicas de solo (Figura 10). 0 máximo consumo de água foi $12.798,14 \mathrm{~mL}_{\text {planta- }}{ }^{-1}$, estimado na dose de $208,61 \mathrm{mg} \mathrm{dm}^{-3} \mathrm{de} \mathrm{P}^{\text {. Nessa dose }}$ de $\mathrm{P}$, as plantas produziram 32,66 g de massa seca total (Figura 9), o que permite depreender sobre a necessidade de $391,86 \mathrm{~mL}$ de água para cada g de massa seca acumulada na planta.

Figura 10 - Consumo de água pelo pinhão-manso em resposta às doses de $\mathrm{P}$ e às compressões físicas ( $\rho s)$.

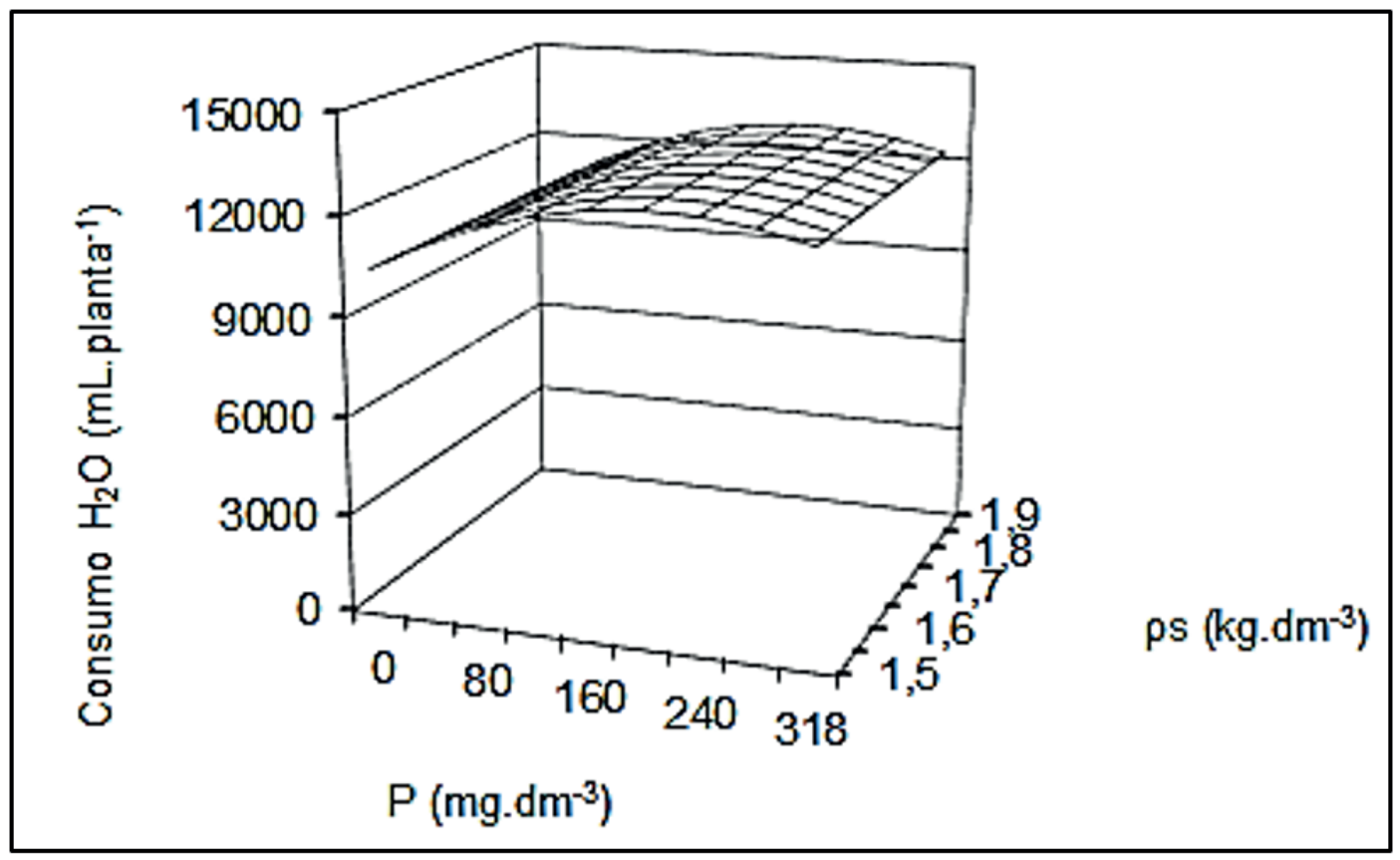

Fonte: Os Autores (2020)

São escassos os trabalhos na literatura que abordam o efeito da adubação em pinhão-manso, considerando plantas em idade produtiva. Marcolan et al. (2014) observaram interação significativa entre adubação de NPK e desenvolvimento da copa. Silva et al. (2015) observaram que a aplicação de fósforo não influenciou a altura das plantas, entretanto aumentou o desenvolvimento dos ramos e do caule e elevou a produção do pinhão-manso. Freiberger (2012) afirma que a ausência da adubação fosfatada é a mais limitante ao crescimento inicial do pinhão-manso, entretanto doses próximas a 50 $\mathrm{mg} \mathrm{dm}^{-3}$ de P são suficientes para promover melhor desenvolvimento inicial da cultura. Esses resultados indicam a importância da adubação fosfatada para o desenvolvimento dessa oleaginosa.

\section{CONCLUSÕES}

A maioria das características de crescimento das plantas de pinhão-manso foi mais influenciada pelas doses de $\mathrm{P}$ comparativamente às compressibilidades aplicadas ao solo. Notadamente, as plantas pouco cresceram, quando se omitiu a adubação fosfatada e não se constatou penetração radicular em solos com massa específica de $1,91 \mathrm{mg} \mathrm{dm}^{-3}$.

0 acúmulo de massa seca pelas plantas foi maior no caule, seguido pelas quantidades verificadas nas raízes e nas folhas. A massa seca total acumulada na planta foi influenciada apenas pelas doses de $\mathrm{P}$, sinalizando que o comprometimento na emissão de raízes em volume de solo com massa 
Crescimento do pinhão-manso em resposta à adubação fosfatada e à compactação de um Latossolo Vermelho Amarelo sob cultivo em ambiente protegido

específica de 1,91 mg dm-3 não foi um fator preponderante no período de condução do experimento. Provavelmente, se o trabalho fosse conduzido por mais tempo, até a produção de sementes pelas plantas, a compactação tivesse um efeito maior ao restringir o volume de solo explorado pelas raízes.

A máxima quantidade de água absorvida foi de 12.798,14 mL planta-1 estimada na dose de 208,61 $\mathrm{mg} \mathrm{dm}^{-3} \mathrm{de}$ P. Nessa mesma dose de $\mathrm{P}$, as plantas produziram $32,66 \mathrm{~g}$ de massa seca total, correspondendo, assim, a um consumo de $391,86 \mathrm{~mL}$ de água para cada g de massa seca acumulada na planta.

\section{REFERÊNCIAS}

BERTONI, J. \& LOMBARDI NETO, F. Conservação do solo. 4. ed. São Paulo, Ícone, 1999. 355p.

CARVALHO, C. M. de.; VIANA, T. V. de A.; MARINHO, A. B.; LIMA JÚNIOR, L. A. de.; VALNIR JÚNIOR, M. Pinhão-manso: crescimento sob condições diferenciadas de irrigação e de adubação no semiárido nordestino. Revista brasileira de engenharia agrícola e ambiental, Campina Grande, v. 17, n. 5, p. 487496, maio 2013.

COSTA, N. V.; ERASMO, E. A. L.; DORNELAS, B. F.; DORNELAS, D. F.; SARAIVA, A. S. Crescimento de plantas de pinhão-manso em resposta à adubação fosfatada: $1^{\circ}$ ano de avaliação. I Congresso Brasileiro de Pesquisa em Pinhão-manso, Brasília, 2009.

EMBRAPA, Empresa Brasileira de Pesquisa Agropecuária. Centro Nacional de pesquisa de Solos. Manual de métodos de análise de solo. 2. ed. Rio de Janeiro, 1997, 212p.

FIRMINO, M. C.; FARIAS, M. S. S.; MEDEIROS, S. S.; GUERRA, H. O. C.; GUIMARÃES, J. P. Altura e diâmetro do pinhão manso sob adubação fosfatada e uso de água residuária. ACSA - Agropecuária Científica no Semiárido, v. 11, n. 2, p. 22-31, 2015.

FREIBERGER, M. B. Crescimento inicial e nutrição do pinhão-manso em função da adubação NPK. 2012. Dissertação (Mestrado) - Universidade Estadual Paulista, Faculdade de Ciências Agronômicas de Botucatu, 2012.

FREIBERGER, M. B.; GUERRINI, I. A.; CASTOLDI, G.; PIVETTA, L. G. Adubação fosfatada no crescimento inicial e na nutrição de mudas de pinhão-manso. Revista Brasileira de Ciência do Solo, Viçosa, v. 38, n. 1, p. 232-239, 2014

JORGE, J. A. Compactação do solo: causas, consequências e maneiras de evitar sua Ocorrência. Campinas, Instituto Agronômico, 1983. 22p. (Circular, 117)

KATO, Érika Miyeko Souza. Conteúdo de água, intensidade e profundidade de compactação sobre o crescimento inicial de Jatropha curcas L. 2012. Dissertação (Mestrado em Agronomia) FCA, Faculdade de Ciências Agrárias - Universidade Federal da Grande Dourados, 2012.

LINHARES, A. C. M.; OLIVEIRA, D. F. S.; GUIMARÃES, L. M.; SILVA, S. S.; COSTA, F. X. Capacidade produtiva do pinhão manso em função da adubação orgânica e mineral no Sertão Paraibano. Magistra, Cruz das Almas, v. 28, n. 1, p. 81-90, 2016.

MALAVOLTA, E. Manual de Nutrição Mineral de Plantas. 1. ed. São Paulo: Editora Agronômica Ceres, 2006. v. 1. 638 p. 
MARCOLAN, A. L.; ROCHA, R. B.; LAVIOLA, B. G.; RAMALHO, A. R.; SANTOS, A. R. dos; BATISTA, H. A. F. Produtividade de grãos e crescimento de pinhão-manso sob diferentes doses de adubação NPK. Porto Velho: Embrapa Rondônia, 2014. (Embrapa Rondônia. Boletim de Pesquisa e Desenvolvimento, 73).

OHLAND, T.; LANA, M. C. do.; FRANDOLOSO, J. F.; RAMPIM, L.; BERGMANN, J. R.; CABREIRA, D. T. Influência da densidade do solo no desenvolvimento inicial do pinhão-manso cultivado em Latossolo Vermelho eutroférrico. Revista Ceres, Viçosa, v. 61, n. 5, p. 622-630, 2014.

Oliveira, E. R.; Silva, T. C.; Ramos, R. F. O. de. Evapotranspiração de referência em Januária-mg pelos métodos tanque classe "A" e Hargreaves-Samani. Colloquium Agrariae, v. 16, n. 01, p. 48-54, 2020.

SATURNINO, H. M.; PACHECO, D. D.; KAKIDA, J.; TOMINAGA, N.; GONÇALVES, N. P. Cultura do pinhãomanso (Jatropha curcas L.). Informe Agropecuário. Belo Horizonte, v. 26, n. 229. p. 44-78, 2005.

SANTOS, R. F.; BORSOI, A.; VIANA, O. A.; VALENTE, V. C. densidades do solo no desenvolvimento de pinhão manso. Revista Varia Scientia Agrárias, v. 02, n.02, p. 21-34, 2012.

SILVA, F. A. S. ASSISTAT 7.5 beta. DEAG-CTRN-UFCG, Campina Grande-PB, 2008.

SILVA, J. T. A. da.; SIMAO, F. R.; ALVES, J. J. M. Desenvolvimento vegetativo e produção do pinhão-manso em resposta à adubação fosfatada. Revista Ceres, Viçosa, v. 62, n. 3, p. 319-322, Jun 2015 . 